\title{
Can Cloze Tests Really Improve Second Language Learners' Reading Comprehension Skills?
}

\author{
Guanxin Ren, Ruyton Girls’ School, Australia
}

\begin{abstract}
Cloze testing is a widely-used procedure to test learners' reading comprehension in learning a language, but little is known if it can really improve learners' reading comprehension skills. This paper attempts to seek answers to this question by comparing the cloze test scores of two groups of students (Experimental versus Control) undertaking Chinese Second Language (CSL) and measuring their Z-score differences. The paper intends to find out if the Experimental Group which received one cloze test per week for a whole school term of 10-week duration could achieve better reading comprehension test results than the Control Group which received no extra cloze tests in between the first and last week of the term. The subjects were 26, Year 10 students aged between 14-15 years old from an independent K-12 boys'school in Melbourne, Australia. They were randomly divided into two separate groups with identical proficiency level in CSL. The cloze tests selected for this study were from the textbook series entitled Boya Chinese-Elementary Start Vol.2 (Li, et al., 2005), which were appropriate to the proficiency level of the subjects. Data were collected in class after each cloze test. Analysis of the data was conducted at the inter-group level examining the standard deviation and Z-scores of each group. The study found that there was not much difference between the two groups. Implications for teaching reading in CSL were discussed, which could also apply to the teaching of reading in other Languages Other Than English (LOTE).
\end{abstract}

Keywords: Cloze tests; reading comprehension; Chinese Second Language (CSL); Languages Other Than English (LOTE)

\section{INTRODUCTION}

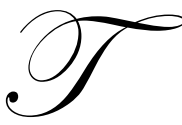

he cloze test, also known as the cloze procedure, has been in practice in language teaching for more than half a century. It was first introduced by Taylor (1953) who intended to measure English nativespeaker children's text readability. To complete a cloze test, the test-taker is required "to reproduce accurately a part deleted from a 'message' (any language product), by deciding from the context that remains, what the missing part should be" (p. 416). In the early 1970s, the cloze test was popularised by Oller (1973) for measuring proficiency in English as a Second Language (ESL). Since then, it has been regarded as a reliable instrument for measuring ESL proficiency (Alderson, 1979; Bachman, 1982).

A review of the existing literature reveals that there are basically three broad areas in which the research on the cloze test has been conducted. The first broad area is related to the structure of the cloze test, e.g., test formats (Helfeldt, et al., 1986; Sachs, et al., 1997), deletion rate (Alderson, 1979; Woods, et al., 1998; Brown, 2002), scoring methods (Henk and Helfeldt, 1985; Hadley and Naaykens, 1997; Litz and Smith, 2006) or comparing the cloze test with other measures (Klein-Braley and Raatz, 1982; Grotjahn, 1987; Woods, et al., 1998).

The second broad area is related to the application of the cloze test. It is claimed that the cloze test can not only measure ESL/EFL proficiency (Fotos, 1989; Kumagai, 1977) but also ESL/EFL discourse competence (Takanashi, 2008), grammar-based proficiency (Hadley and Naaykens, 1997), EFL language ability (Kimie, 1983), reading behaviour (Rye, 1982; Powell, 1988) and ESL reading comprehension (Weaver, 1979; Jonz, 1991; 
Yamashita, 1994; Fletcher, 2006; Paris, 2007). Besides, the cloze test can also be used for plagiarism detection (Glatt and Haertel, 1982; Standing and Gorassini, 1989), predicating interpreting and translation proficiency (Donahoe and Lim, 2007), comparing human versus machine translation (Sinaiko and Klare, 1972, 1973; Harold and Wild, 2000), evaluating instructional programs (Bormuth, 1967), for reading recovery (Wheldall, et al., 1995), improving reading skills in adult deaf (Ferrer, et al., 2002), evaluating the reading of hearing impaired children (Girgin, 2007) or aphasic adults (Bogdanoff and Katz, 1983) or evaluating readability of the pharmacy-relevant reading materials (Miller and DeWitt, 2009), the health leaflets (Wilson, et al., 1997) or the reading materials concerning tourism (Woods, et al., 1998).

The third broad area where the cloze test research has focused its attention on is to critically review the cloze test and further refine its procedure. For instance, it was found that the deletion rate could affect test-takers' performance (Alderson, 1979); different word deletion could end up with different test results (Brown, 2002); shorter passages could make the cloze test less reliable (Woods, et al., 1998); and some test-takers would be frustrated by the cloze test in comparison with other measures (Hecker, et al., 1980). Following these critical reviews, modification of the original cloze test format has been made or alternative measures have been introduced.

Although numerous studies have been undertaken to refine the cloze procedure, very little is known if the cloze test per se can improve CSL students' reading comprehension skills. The present study attempts to take a closer look at this issue and find answers to this question.

The significance of this study is that it will help refine our current understanding of the cloze test and provide us with some insight into the function of the cloze test in the teaching of not only CSL but also other LOTE. This study will make a contribution to the function of the cloze test by way of bridging the gap in the literature where the three broad areas of research stated previously have not touched otherwise.

\section{METHODS}

\section{Subjects}

The subjects of this study were 26 senior secondary school students aged between 14 and15 from an independent boys' school in Melbourne, Australia. Among them, $88 \%$ were born in Australia and 4\% in the United States of America, Singapore and China respectively. In the case of the latter, although the birthplace was in China, the subject did not reside there for over 12 months nor receive any formal education in Chinese in a school in China; therefore, he is qualified to be a CSL learner by following the selection criteria specified in the Study Design for Chinese Second Language (2008-2010) by the Victorian Curriculum and Assessment Authority (VCAA, 2008). As far as the length of learning CSL in Australia is concerned, 50\% of the subjects have studied CSL for 3 years before commencing this case study and 50\% for more than 3 years. However, one noticeable point about these two groups is that the subjects from the Experimental Group have a slightly longer history of learning CSL in comparison with the Control Group as 31\% of the subjects from the Experimental Group have studied CSL for 3 years and 69\% for over 3 years, but this situation is reversed in the Control Group (i.e., $69 \%$ for 3 years and $31 \%$ for over 3 years). In this case, the Experimental Group seems to have an advantage over the Control Group in terms of length of learning CSL, so it would be logical to think that the Experimental Group's test results should be better than that of the Control Group. Whether this holds true is also to be explored in this study.

\section{Materials}

Used in this study were 10 cloze tests developed from the textbook series entitled Boya Chinese (Li, et al., 2005) published by Peking University Press. The volume selected is Boya Chinese - Elementary Start Vol.2 which is most suitable for the subjects of this study as it has a similar entry vocabulary requirement (approximately 500 characters) to the prescribed textbook Hanyu Jiaocheng Book 2, Part 1 (Yang, et al., 2003) used by the subjects; therefore, the selection is appropriate to the proficiency level of the subjects.

There were totally 156 test papers prepared for this study with the Experimental Group having attempted 130 and the Control Group 26. The deletion rate was every $7^{\text {th }}$ character in a chosen passage and there were approximately 30-35 items in each character passage. This restriction was necessary due to the fact that the subjects 
had to complete each cloze test within one contact period of 40-minute duration timetabled in the existing curriculum setup. All the cloze passages in this study were scored using both exact-answer scoring and acceptableanswer scoring methods.

\section{Procedures}

Two Year 10 Chinese classes ( $n=16$ vs. $n=13$ ) were invited to participate in this study at the beginning of Term 3, 2009. A 14-item questionnaire was given to all of them to assess their language background. The factors considered include birth place, residence, length of learning CSL, language spoken at home and so on. The results of the survey showed that although all 29 students were qualified as the CSL learners by following the selection criteria published by VCAA (2008), 3 of them from the first class $(n=16)$ either studied Chinese outside school for more than 10 years before entering Year 10 or spoke Mandarin at home; therefore, these 3 students were excluded from the data. Finally, 13 from each class were chosen to participate in this study. This made the comparison of data fairer and more comparable. The class which was reduced its size from 16 to 13 was nominated as Experimental Group and the other which had 13 in its original composition was nominated as Control Group. Both groups were given a cloze test at the beginning of Term 3, 2009 and after 10 weeks of study, they were given another cloze test of which the degree of difficulty in content was progressively increased in comparison with the first test. One significant difference concerning the Experimental Group was that they were given eight extra cloze tests between the first and the $10^{\text {th }}$ cloze tests whereas the Control Group was given none in between. This was deliberate because it was intended to find out if the Experimental Group could actually do better in the $10^{\text {th }}$ cloze test in comparison with the Control Group.

\section{Test score standardisation}

After all the cloze test scores from both groups were tabulated, the raw scores had to be standardised in order to make the comparison of the test scores achieved by both groups comparable. There were three sets of scores used in this process: the aggregate mean, the standard deviation and the Z-scores. In this study, as using the former two could only allow us to compare scores within the normal distribution, we have to use Z-scores, because Z-scores allow us to compare two scores that are from different distributions with different means and standard deviations.

\section{DATA PRESENTATION AND ANALYSIS}

The repertoire of the data collected during the 10-week teaching period contained the scores of 156 cloze test papers undertaken by the two groups. These scores were timely recorded after each test using the Excel worksheet. Z-scores were derived from each test score based on the aggregate mean and the standard deviation of each group. Below are the results of the Experimental Group:

Table 1: Test results achieved by the Experimental Group

\begin{tabular}{|c|c|c|c|c|c|}
\hline Experimental Group & Cloze Test 1 & Z-Scores & Cloze Test 10 & Z-Scores & Changes in Z-Scores Direction \\
\hline 1 & 63 & 1.28 & 45 & 0.45 & -0.83 \\
\hline 2 & 50 & 0.56 & 70 & 1.70 & +1.14 \\
\hline 3 & 37 & -0.17 & 38 & 0.10 & +0.27 \\
\hline 4 & 57 & 0.95 & 40 & 0.20 & -0.75 \\
\hline 5 & 47 & 0.39 & 35 & -0.05 & -0.44 \\
\hline 6 & 23 & -0.96 & 15 & -1.05 & -0.09 \\
\hline 7 & 30 & -0.56 & 25 & -0.55 & +0.01 \\
\hline 8 & 20 & -1.13 & 13 & -1.15 & -0.02 \\
\hline 9 & 17 & -1.29 & 8 & -1.40 & -0.11 \\
\hline 10 & 33 & -0.40 & 25 & -0.55 & -0.15 \\
\hline 11 & 30 & -0.56 & 40 & 0.20 & +0.76 \\
\hline 12 & 37 & -0.17 & 38 & 0.10 & +0.27 \\
\hline 13 & 77 & 2.07 & 75 & 1.95 & -0.12 \\
\hline mean & 40.1 & & 35.9 & & \\
\hline sd. & 17.8 & & 20.0 & & \\
\hline
\end{tabular}


Table 1 above shows the results of Cloze Test 1 and 10 attempted by the Experimental Group. Checking the Z-scores of each individual within the Experimental Group, we can see that although there are some Z-score changes upwards among the individuals within this group, the overall change of Z-scores, as far as the entirely group is concerned, is going downwards reaching 0.06 standard deviation below the aggregate mean. Now, let us compare it with the Control Group:

Table 2: Test results achieved by the Control Group

\begin{tabular}{|c|c|c|c|c|c|}
\hline Control Group & Cloze Test 1 & Z-Scores & Cloze Test 10 & Z-Scores & Changes in Z-Scores Direction \\
\hline 1 & 20 & -0.88 & 10 & -1.05 & -0.17 \\
\hline 2 & 43 & 0.27 & 45 & 1.07 & +0.80 \\
\hline 3 & 17 & -1.03 & 8 & -1.17 & -0.14 \\
\hline 4 & 83 & 2.27 & 60 & 1.98 & -0.29 \\
\hline 5 & 33 & -0.23 & 35 & 0.46 & +0.69 \\
\hline 6 & 27 & -0.53 & 20 & -0.45 & +0.08 \\
\hline 7 & 23 & -0.73 & 18 & -0.57 & +0.16 \\
\hline 8 & 37 & -0.03 & 18 & -0.57 & -0.54 \\
\hline 9 & 60 & 1.12 & 38 & 0.64 & -0.48 \\
\hline 10 & 17 & -1.03 & 8 & -1.17 & -0.20 \\
\hline 11 & 63 & 1.27 & 45 & 1.07 & -0.19 \\
\hline 12 & 30 & -0.38 & 18 & -0.57 & +0.37 \\
\hline 13 & 37 & -0.03 & 33 & 0.34 & \\
\hline mean & 37.7 & & 27.4 & & \\
\hline sd. & 20.0 & & 16.5 & & $-\mathbf{0 . 0 5}$ \\
\hline Croup Overall & & & & & \\
\hline Change & & & & & \\
\hline
\end{tabular}

Table 2 above shows the Z-scores in both tests attempted by the Control Group. Similarly to the Experimental Group, there are some movements of Z-scores among the individual members of the group upwards from the first test to the last, but when the Z-scores of both tests were combined, we have found that the overall change of Z-scores in both tests attempted by the Control Group is going down reaching 0.05 standard deviation below the aggregate mean. This means that there is no much difference between the two groups' Z-scores (-0.06 vs. $-0.05)$.

Now let us compare the two groups' Z-scores from another angle to see if there is any difference between the two groups. Consider

Table 3: Comparison of Z-Scores of Cloze Test 1 and 10 Combined Attempted by both Groups

\begin{tabular}{|c|c|c|}
\hline $\begin{array}{c}\text { Group Member } \\
\text { ID }\end{array}$ & $\begin{array}{c}\text { Changes in Z-Scores of Tests 1 \& 10 } \\
\text { Combined Achieved by Experimental } \\
\text { Group }\end{array}$ & $\begin{array}{c}\text { Changes in Z-Scores of Tests 1 \& 10 } \\
\text { Combined Achieved by Control Group }\end{array}$ \\
\hline 1 & -0.83 & -0.17 \\
\hline 2 & +1.14 & +0.80 \\
\hline 3 & +0.27 & -0.14 \\
\hline 4 & -0.75 & -0.29 \\
\hline 5 & -0.44 & +0.69 \\
\hline 6 & -0.09 & +0.08 \\
\hline 7 & +0.01 & -0.16 \\
\hline 8 & -0.02 & -0.54 \\
\hline 9 & -0.11 & -0.48 \\
\hline 10 & -0.15 & -0.14 \\
\hline 11 & +0.76 & -0.19 \\
\hline 12 & +0.27 & +0.37 \\
\hline 13 & -0.12 & $38 \%$ \\
\hline Group's Overall Sd. Above Mean & $38 \%$ & $62 \%$ \\
\hline Group's Overall Sd. Below Mean & $62 \%$ & \\
\hline
\end{tabular}


Table 3 above shows the up-and-down movement of the Z-scores close to the aggregate mean of Cloze Test 1 and 10 combined attempted by both groups. It is clearly indicated that the percentage of the up movement of the Z-scores achieved by the Experimental Group is the same as the Control Group and the same holds true for the down movement of the Z-scores of each group. This means that, ultimately, there is no difference between the two groups as far as the changes in Z-scores are concerned.

\section{FINDINGS}

It has been found in this study that cloze tests per se do not help CSL learners achieve better results in reading comprehension tests. As shown in this study, the Z-scores of the Experimental Group which has undertaken the cloze test five times more than the Control Group, yet their Z-scores are more or less the same as those of the Control Group. This finding is significant as it clearly indicates that the more cloze tests one sits for does not mean that one will do better in reading comprehension tests. This has busted the myth that the more one does the better one can be, which has influenced people not only in the field of language study but also in many other fields as well.

The second important finding of this study is that the length of learning CSL does not automatically produce a better reader in the target language. On average, the Experimental Group has a record of longer years of learning CSL, but their final test results are almost the same as the Control Group. This will make us re-think about the thought that the longer one spends time learning a language, the better one will be good at it. The truth is that all will depend upon how well it is taught and learnt rather than how long it has been practised.

\section{IMPLICATIONS FOR TEACHING READING IN CSL AND OTHER LOTE}

The findings of this study imply that good reading comprehension skills need to be taught rather than by attempting a number of different cloze tests. Then, the question remains: what reading strategies can help CSL and other LOTE students gain good reading comprehension skills? Lehr and Osborn (2005) reported that based on a review of 205 studies, the National Reading Panel (2000) identified 16 categories of reading strategies among which comprehension monitoring, using graphic and semantic organisers, using the structure of stories, answering questions, generating questions, and summarising seemed to be the most effective; therefore, it is suggested that these reading strategies should be adopted and taught in CSL and other LOTE. To be more specific, CSL and other LOTE students should be taught Question-Answer Relationships (GAR) (Raphael, 1986) which focuses on helping students learn to ask themselves questions about what they read. They should also be taught Transactional Strategy Instruction (TSI) which helps students link their prior knowledge to a text through discussion and in the meantime involves themselves in constructing meaning as a result of the group discussion (Brown and Coy-Ogan, 1993; Schuder, 1993; Brown, et al., 1996).

Other effective reading strategies relevant here include: Concept-Oriented Reading Instruction (CORID) (Guthrie, et al., 1996, 1999, 2000), Students Achieving Independent Learning (SAIL) (Pressley, et al., 1992), Summarising-Contextualising-Inferring-Monitoring-Corroborating (SCIM-C) (Hicks, et al., 2004) and SurveyQuestion-Read-Recite-Review-Reflect (SQ4R) (Richardson and Morgan, 1997). In addition, the Mind Map technique originated by Buzan (2000) should also be taught in CSL and other LOTE classrooms because it is an effective strategy in learning which can help learners organise their reading materials through symbols, signs and colour, which will enhance their memory of the materials read.

\section{CONCLUSION}

Considering the extra number of cloze tests the Experimental Group attempted between the first and the last test within the 10-week teaching period and the time and effort this group has put into learning CSL, it is disappointing to see the test results the Experimental Group has achieved. The subjects in the Experimental Group have literally achieved no more than what those in the Control Group have achieved within the same timeframe. This finding is very significant because it suggests that the cloze test which is regarded as a good tool for improving students' reading comprehension skills may be a perception only. The fact is that it is not true; therefore, it is time for us to re-focus on the teaching of the claimed effective reading strategies in order to improve CSL and other LOTE learners' reading comprehension. 


\section{AUTHOR INFORMATION}

Dr Guanxin Ren teaches Chinese at Ruyton Girls' School in Melbourne, Australia. He can be contacted at reng@cruyton.vic.edu.au. For his other refereed articles on Chinese language teaching, see Babel, 43,3, 2009; Babel, 42,2, 2007; NZALT Conference Proceedings (Refereed Section) 2006; Babel, 39, 1, 2004; Languages Victoria, 8, 1, 2004; and Babel, 37.3, 2003.

\section{REFERENCES}

1. Alderson, J.C. 1979. The cloze procedure and proficiency in English as a second language. TESOL Quarterly, 13, 219-226.

2. Altman, E. 1968. Financial ratios, discriminant analysis and the prediction of corporate bankruptcy. The Journal of Finance, 23, 4, 589-609.

3. Bachman, L. 1982. The trait structure of cloze test scores. TESOL Quarterly, 16, 61- 70.

4. Bogdanoff, M. G. and Katz, R. C. 1983. Modification of the cloze procedure for measuring reading levels in aphasic adults. Paper presented at Clinical Aphasiology Conference, May 29-June 2, 1983, Phoenix, AZ, BRK Publishers (1983), pages 28-34.

5. Bormuth, J.R. 1967. Cloze readability procedure. CSEIP Occasional Report No.1 (24 pages) Retrieved January 5, 2010 from: http://www.cse.ucla.edu/products/reports/R004.pdf

6. Brown, J. D. 2002. Do cloze tests work? Or, is it just an illusion? Second Language Studies, 21, 1, 79-125.

7. Brown, R., and Coy-Ogan, L. 1993. The evolution of transactional strategies instruction in one teacher's classroom. The Elementary School Journal, 94, 221-233.

8. Brown, R., Pressley, M., Van Meter, P. and Schuder, T. 1996. A quasi-experimental validation of transactional strategies instruction with low-achieving second-grade readers. Journal of Educational Psychology. 88, 1, 18-37.

9. Buzan, T. 2000. The Mind Map Book: Unlock Your Creativity, Boost Your Memory, Change Your Life. Penguin Books.

10. Donahoe, B. and Lim, H.O. 2007. Cloze tests: a predictor of interpreting and translating proficiency? Language and Linguistics, 20, 151-168.

11. Ferrer, A., Romero, R., Martínez, $M^{\mathrm{a}}$.C., Asensi, M ${ }^{\mathrm{a}}$.C. y Andreu, A. and Acceso, R.U. 2002. Improving reading skills in adult deaf people: the Spanish MÀS Module. Retrieved January 5, 2010 from: acceso.uv.es/mas/conference2002/papers/2002_Berlin_ACCESO_en.pdf

12. Fletcher, J.M. 2006. Measuring reading comprehension. Scientific Studies of Reading. 10, 3, 323-330.

13. Fotos, S.S. 1989. The cloze test as an integrative measure of EFL proficiency: a substitute for essays on college entrance examinations. Paper presented at the Second International Testing Conference held at The University of Tsukuba, Ibaraki, Japan, March 1989.

14. Girgin, Ü. 2007. Evaluation of hearing impaired students' reading comprehension with the cloze procedure. Paper presented at the $7^{\text {th }}$ International Educational Technology Conference, Nicosia, Turkish Republic of Northern Cyprus, May 3-5 2007.

15. Glatt, B.S. and Haertel, E.H. 1982. The use of the cloze testing procedure for detecting plagiarism. Journal of Experimental Education, 50, 3, 127-136.

16. Grotjahn, R. 1987. How to construct and evaluate a c-test: a discussion of some problems and some statistical analyses. In Rudiger G., Klein-Braley, C. and Stevenson, D.K. (eds.). Taking Their Measure: The Validity and Validation of Language Tests (pp.219-253). Bochum: Brockmeyer.

17. Guthrie, J. T., Van Meter, P. McCann, A. D. and Wigfield, A. 1996. Growth of literacy engagement: changes in motivations and strategies during concept-oriented reading instruction. Reading Research Quarterly, 31, 306-332.

18. Guthrie, J. T., Anderson, E., Alao, S., and Rinehart, J.1999. Influences of concept-oriented reading instruction on strategy use and conceptual learning from text. Elementary School Journal, 99, 343-366.

19. Guthrie, J. T., Wigfield, A., and VonSecker, C. 2000. Effects of integrated instruction on motivation and strategy use in reading. Journal of Educational Psychology, 22, 331-341.

20. Hadley, G. and Naaykens, J. 1997. An investigation of the selective deletion cloze test as a valid measure of grammar-based proficiency in second language learning. Niigata Studies in Foreign Languages and Cultures 3,111-118. 
21. Harold, S. and Wild, E. (2000). Evaluating machine translation: the cloze procedure revisited. Translating and the Computer, 22. Retrieved January 10, 2010 from:

http://personalpages.manchester.ac.uk/staff/harold.somers/Aslib2000.doc

22. Hecker, N.M., Jerrolds, B. and Benton, S.E. 1980. The space test as a possible new informal reading placement test. Paper presented at the Annual Meeting of the American Reading Conference (1 st, Sarasota, FL, December 4-6, 1980).

23. Helfeldt, J.P., Henk, W.A., Fotos, A., 1986. A test of alternative cloze test formats at the sixth-grade level. Journal of Educational Research, 79, 4, 216-221.

24. Henk, W.A. and Helfeldt, J.P. 1985. Effects of alternative deletion patterns, blank conditions, and scoring systems on intermediate level of cloze test performance. Reading Psychology, 6, 1 \& 2, 85-96.

25. Hicks, D., Doolittle, P.E., and Ewing, T. 2004. The SCIM-C strategy: expert historians, historical inquiry, and multimedia. Social Education, 68, 3, 221-225.

26. Jonz, J. 1991. Cloze item types and second language comprehension. Language Testing, 8, 1-22.

27. Klein-Braley, C. and Raatz, U. 1984. A survey of research on the c-test. Language Testing, 1, 2, 134-146.

28. Kimie, S. 1983. Measurement of Japanese language ability by the cloze methods. International Christian University Publications - I-A Educational Studies, 25, 141-178.

29. Kumagai, M. 1977. The use of the cloze test in the EFL classroom. Modern Language Testing, N.Y.: HarcOurt, 15-18.

30. Lehr, F. and Osborn, J. 2005. A focus on comprehension. Pacific Resources for Education and Learning The Research-Based Practices in Early Reading Series, No. 3, 1-50.

31. Li, X., Xu, J., and Ren, X. 2005. Boya Chinese-Elementary Start (Vol.2). Beijing: Peking University Press.

32. Liz, D.R., and Smith, A.K. 2006. Semantically acceptable scoring procedures (SEMAC) versus exact replacement scoring methods (ERS) for 'cloze' tests: a case study. Asian EFL Journal, 8, 1, Article 2,

33. Miller, M.J. and DeWitt, J.E. 2009. Application of the cloze procedure to evaluate comprehension and demonstrate rewriting of pharmacy educational materials. The Annals of Pharmacotherapy, 43, 4, 650-657.

34. National Reading Panel. 2000. Teaching children to read: An evidence-based assessment of the scientific research literature on reading and its implications for reading instruction. Washington, DC: National Institute of Child Health and Human Development.

35. Oller, J.W.Jr. 1973. Cloze tests of second language proficiency and what they measure. Language Learning, 23, 105-118.

36. Paris, S.G. 2007. Assessment of reading comprehension. Encyclopaedia of Language and Literacy Development (pp. 1-8). London, ON: Canadian Language and Literacy Research Network.

37. Powell, J. L. 1988. An examination of comprehension processes used by readers as they engage in different forms of assessment. Unpublished Doctoral Dissertation, Indiana University, 1-196.

38. Pressley, M., El-Dinary, P. B., Gaskins, I., Schuder, T., Bergman, J., Almasi, L. 1992. Beyond direct explanation: transactional instruction of reading comprehension strategies. Elementary School Journal, 92 , $5,513-555$.

39. Price, I. 2000. Research methods and statistics PESS202 lecture and commentary notes. Retrieved 26 September 2010 from: http://www.une.edu.au/WebStat/unit materials/index.htm

40. Raphael, T. E. 1986. Teaching question-answer relationships, revisited. The Reading Teacher, 39, 516-522.

41. Richardson, J. and Morgan, R. 1997. Reading to learn in the content areas. Belmont, CA: Wadsworth Publishing Company.

42. Rye, J. 1982. Cloze Procedure and the Teaching of Reading. Portsmount, NH: Heinemann Educational Books Inc.

43. Sachs, J., Tung, P. and Lam, R. 1997. How to construct a cloze test: lessons from testing measurement theory models. Perspectives, 9, 145-160.

44. Schuder, T. 1993. The genesis of transactional strategies instruction in a reading program for at-risk students. The Elementary School Journal, 94, 183-200.

45. Sinaiko, H.W. and Klare, G.R. 1973. Further experiments in language translation: a second evaluation of the readability of computer translations. ITL 19, 29-52.

46. Standing, L. and Gorassini, D. 1986. An evaluation of the cloze procedure as a test for plagiarism. Teaching of Psychology, 13, 3, 130-132.

47. Takanashi, Y. 2008. Can cloze tests measure discourse competence in ESL/EFL appropriately? Bulletin of Fukuoka University of Education, 57, 1, 47-57. 
48. Taylor, W.L. 1953. Cloze procedure: A new tool for measuring readability. Journalism Quarterly, 30, 415433.

49. VCAA. 2008. The Victorian Curriculum Assessment Authority. Retrieved January 8, 2010 from: http://www.vcaa.vic.edu.au/vce/studies/lote/chinese2nd/chin2ndindex.html

50. Weaver, P.A. 1979. Improving reading comprehension: effects of sentence organization instruction. Reading Research Quarterly, 15, 1, 129-146.

51. Wheldall, K., Center, Y., Freeman, L., Outhred, L. and McNaught, M. 1995. An experimental evaluation of reading recovery. Reading Research Quarterly, 30, 240-263.

52. Wilson, R., Kenny, T. Clark, J. Moseley, D., Newton, L., Newton, D., and Purves, I. 1997. Ensuring the readability and understandability and efficacy of patient information leaflets. PILs Project Summary Report, UK: University of Newcastle.

53. Woods, B., Moscardo, G., and Greenwood, T. (1998). A critical review of readability and comprehensibility tests. The Journal of Tourism Studies, 9, 2, 49-61.

54. Yamashita, S.O. 1994. Is the reading comprehension performance of learners of Japanese as a second language the same as that of Japanese children? An analysis using a cloze test. Japanese Education in the World, 4, 6, 133-146.

55. Yang, J., Qiu, J., and Zhu, Q. 2003. Jiaocheng Book 2, Part 1. Beijing; Beijing Languages University Press. 